ORIGINAL RESEARCH ARTICLE

\title{
Trends and Determinants of Comprehensive Knowledge of HIV among Adolescents and Young Adults in Nigeria: 2003 - 2013
}

\author{
Ayodeji B. Oginni ${ }^{1}$, Sylvia B. Adebajo ${ }^{1}$, Babatunde A. Ahonsi ${ }^{2}$ \\ Population Council, Nigeria ${ }^{1}$, United Nations Population Fund, Beijing, China ${ }^{2}$ \\ *For Correspondence: Email: oginnia@ipas.org; Phone: +234 9093208837
}

\begin{abstract}
This study examined comprehensive knowledge of HIV (CKH) and its determinants among young people aged 15-24 years in Nigeria between 2003 and 2013. Secondary analysis was conducted on three rounds of NDHS 2003, 2008 and 2013 data. CKH increased significantly between 2003 and 2013, but the level reached in 2013 fell short of the global expectation for young people. Its significant determinants included gender, age, educational attainment, place and region of residence, household wealth status and uptake of HIV test. There is need to sustain all on-going effective youth-focused interventions and programmes to meet the comprehensive knowledge needs for all young people in Nigeria. (Afr J Reprod Health 2017; 21 [2]: 26-34).
\end{abstract}

Keywords: Young people, HIV and AIDS, Comprehensive knowledge, Nigeria, Determinants

\section{Résumé}

Cette étude a examiné la connaissance approfondie du VIH (CCV) et ses déterminants chez les jeunes gens âgés de 15 à 24 ans au Nigeria entre 2003 et 2013. Une analyse secondaire a été menée sur trois séries de données de NDHS 2003, 2008 et 2013. La CCV a augmenté de manière significative entre 2003 et 2013, mais le niveau atteint en 2013 était inférieur aux attentes mondiales pour les jeunes. Ses déterminants importants comprennent le genre, l'âge, le niveau de scolarité, le lieu et la région de résidence, l'état de la richesse des ménages et l'adoption de l'analyse pour le dépistage du VIH. Il est nécessaire de soutenir toutes les interventions et programmes efficaces axés sur les jeunes pour répondre aux besoins globaux en connaissances de tous les jeunes du Nigeria. (Afr J Reprod Health 2017; 21 [2]: 26-34).

Mots-clés: Jeunes, VIH et SIDA, connaissance compréhensive, Nigeria, déterminants

\section{Introduction}

With $3.2 \%$ HIV prevalence, 3.4 million persons living with HIV and 170,000 new infections, Nigeria contributes the world's second highest number of persons living with HIV and $10 \%$ of new HIV infections ${ }^{1-3}$. Although HIV prevalence is reported to have declined in the general adult $(\geq 25$ years) population by 18\% between 2007 and 2012, there has been a concomitant increase in prevalence by $25 \%$ from $2.4 \%$ to $3.0 \%$ among youth $15-24$ years during the same period ${ }^{4,5}$. While it is not known what proportion of estimated annual new HIV infections occur among young persons (age 15-24) in Nigeria, there is a postulation that more than half of those newly infected with HIV today are between 15 and 24 years old ${ }^{6}$.
Comprehensive and accurate knowledge of HIV measured by the UN General Assembly on AIDS (UNGASS) knowledge indicator as percentage of young people aged 15-24 who both correctly identify ways of preventing the sexual transmission of HIV and who reject major misconceptions about HIV transmission is essential for behavior change $e^{7,8}$. There is mounting evidence of the correlation between increased comprehensive knowledge and reduction in HIV incidence and prevalence in regions characterized by high HIV prevalence ${ }^{9-11}$. Globally, evidence has shown that despite the high level of awareness of HIV among youth, comprehensive knowledge of HIV remains unacceptably low, even in countries most affected by the epidemic ${ }^{8,11}$. Assessing the level of knowledge of HIV among youth is vital for monitoring HIV prevention programs, identifying 
gaps and refining activities ${ }^{12}$. This study was undertaken to examine trends and determinants of comprehensive knowledge of HIV among young people aged 15-24 in Nigeria between 2003 and 2013.

\section{Methods}

\section{Data sources and study population}

The study data were obtained on request from the Demographic and Health Surveys (DHS) Program, ICF International. Three primary datasets of men and women of reproductive ages from the 2003, 2008 and 2013 Nigeria Demographic and Health Surveys (NDHS) conducted in Nigeria were obtained from the DHS Program. The datasets were trimmed down and pooled to contain a study population of young people aged 15-24 years.

\section{Study variables}

The dependent variable, comprehensive knowledge of HIV was measured as a composite score of the following elements - accepting common ways of preventing HIV (being faithful, correctly and consistently using condom and agreeing that a healthy-looking person can be infected with HIV) and rejecting two most common local misconceptions of HIV transmission (HIV can be transmitted by mosquito bites and HIV can be transmitted by supernatural means). A binary outcome of "1" was designated if all questions were answered correctly and " 0 " if any of the questions was answered incorrectly ${ }^{13-15}$.

The independent variables of interest were selected based on literature ${ }^{12,16-24}$ and availability in the dataset; the variables were: survey year, age, gender, education, marital status, place of residence, region of residence, household wealth index, ${ }^{1}$ and previous uptake of HIV test.

\section{Statistical analysis}

To ensure representativeness of our study results, we applied sampling weights to the analyses to adjust for non-response and differences in probability of selection. Meta-analysis was conducted to pool the three survey years' crude relative risk ratio estimates (CRR, 95\% CI) of association between the dependent and the independent variables. Using Log-binomial regression analysis, a generalized linear regression model was obtained with adjusted relative risk ratio estimates (ARR, 95\% CI) for each category of the independent variables in the model relative to its reference category. The analyses were conducted with Stata /SE 11.0 for Windows.

\section{Results}

Females predominated $(>69.0 \%)$ in each survey period and slightly more than half of all respondents were 15-19 years (Table 1). Over 70\% of the respondents had formal education, with more than half $(<52.0 \%)$ having at least secondary education and many $(>61.0 \%)$ were single. More than half of the respondents resided in rural areas and about one-third resided in poor households. Although proportion of respondents who reported ever testing for HIV was very low across the study periods, there was an increase from $6 \%$ to $10 \%$ and $16 \%$ in 2003, 2008 and 2013 respectively. Proportion of respondents with comprehensive knowledge of HIV increased from $15.3 \%$ in 2003 to $25.1 \%$ and $27.1 \%$ in 2008 and 2013 respectively. (Table 1)

Table 2 presents the pooled crude estimates of association between comprehensive knowledge of HIV among young people and their selected characteristics. The analysis showed that females were less likely to have comprehensive knowledge of HIV than males; those aged 20-24 were more likely to have comprehensive knowledge of HIV than those aged 15-19; while comprehensive knowledge of HIV significantly increased with formal education, it reduced with being currently married. Also, youth residing in rural areas were less likely to have comprehensive knowledge of HIV than those in the urban areas; and compared to persons from the northern regions of Nigeria, those from the southern regions were more likely to have comprehensive knowledge of HIV. Furthermore, comprehensive knowledge of HIV increased significantly with household wealth 
Table 1: Characteristics of Study Populations

\begin{tabular}{|c|c|c|c|}
\hline & $\begin{array}{l}\text { NDHS } \\
2003 \\
\%\end{array}$ & $\begin{array}{l}\text { NDHS } \\
2008 \\
\%\end{array}$ & $\begin{array}{l}\text { NDHS } \\
2013 \\
\%\end{array}$ \\
\hline \multicolumn{4}{|l|}{ Sex } \\
\hline Male & 21.5 & 28.0 & 30.9 \\
\hline Female & 78.5 & 72.0 & 69.1 \\
\hline \multicolumn{4}{|l|}{ Age } \\
\hline $15-19$ & 53.0 & 51.5 & 54.2 \\
\hline $20-24$ & 47.0 & 48.5 & 45.8 \\
\hline \multicolumn{4}{|l|}{ Education } \\
\hline None & 27.1 & 23.4 & 26.2 \\
\hline Primary & 20.1 & 14.5 & 12.2 \\
\hline Secondary & 48.4 & 56.0 & 55.6 \\
\hline Higher & 4.4 & 6.2 & 6.0 \\
\hline \multicolumn{4}{|l|}{ Marital status } \\
\hline Never married & 61.0 & 65.3 & 65.3 \\
\hline Currently married & 37.2 & 33.7 & 33.5 \\
\hline Formerly married & 1.8 & 1.9 & 1.2 \\
\hline \multicolumn{4}{|l|}{ Religion } \\
\hline Christians & 52.1 & 56.0 & 46.8 \\
\hline Muslims & 47.3 & 42.5 & 52.0 \\
\hline Others & 0.6 & 1.4 & 1.2 \\
\hline \multicolumn{4}{|l|}{ Place of residence } \\
\hline Urban & 35.3 & 36.4 & 42.7 \\
\hline Rural & 64.7 & 63.6 & 57.3 \\
\hline \multicolumn{4}{|l|}{ Region } \\
\hline Northern & 56.9 & 50.2 & 60.9 \\
\hline Southern & 43.1 & 49.8 & 39.1 \\
\hline \multicolumn{4}{|c|}{ Household Wealth Index } \\
\hline Poor & 34.1 & 34.4 & 35.7 \\
\hline Average & 20.7 & 19.9 & 21.1 \\
\hline Rich & 45.3 & 45.7 & 43.2 \\
\hline \multicolumn{4}{|l|}{ Had HIV test before } \\
\hline No & 81.6 & 86.7 & 83.0 \\
\hline Yes & 5.5 & 10.0 & 16.3 \\
\hline No response & 12.9 & 3.3 & 0.7 \\
\hline \multicolumn{4}{|c|}{ Comprehensive knowledge } \\
\hline No & 84.7 & 74.9 & 72.9 \\
\hline Yes & 15.3 & 25.1 & 27.1 \\
\hline $\mathrm{N}$ & 4089 & 17664 & 21167 \\
\hline
\end{tabular}

${ }^{1}$ The DHS wealth index indicates inequalities in household characteristics, in the use of health and other services, and in health outcomes. It serves as an indicator of wealth that is consistent with expenditure and income measures. The index was constructed using household asset data via a principal components analysis.

and previous reports of uptake of HIV test. (Table 2)

Table 3 presents the results of the multivariate analysis of the pooled data. The multivariate model controlled for the confounding effects of each variable and presented adjusted relative risk ratio estimates. The results indicate that comprehensive knowledge of HIV among young people in 2013 increased 1.5 times the level in 2003. Whilst female adolescents and young adults, those residing in rural areas, and those located in Southern Nigeria were less likely to have comprehensive knowledge of HIV; it increased significantly with age, formal education, household wealth and previous uptake of HIV test. (Table 3)

\section{Discussion}

In sub-Sahara Africa, comprehensive knowledge of HIV remains low $^{10,25}$, A review of Demographic and Health Surveys (DHS) from countries across West Africa from 2003-2008 estimated that less than $50 \%$ of the population between the ages of 15 and 49 had adequate correct knowledge about HIV/AIDS ${ }^{10,25}$. This is also evident from the findings of this study. Comprehensive knowledge of HIV among young people in Nigeria increased between 2003 and 2013, but the increase fell short of the universal target of $95 \%$ by 2010 for HIV knowledge among young people $e^{9,11,26}$. A previous study conducted among young people aged 10-24 years in two states in Nigeria, showed that despite the high level of awareness about HIV, knowledge of transmission and basic HIV prevention facts was ${ }^{2}{ }^{23}$. In contrast, Liberia achieved a level above $50 \%$ among young men and women aged 15-24 in the same period ${ }^{9}$. Also in Kenya, a higher increase in comprehensive knowledge of HIV from $22 \%$ in 2003 to $54 \%$ in 2008/09 was recorded among urban female youth ${ }^{16}$. However, it is believed that opportunities to improve HIV prevention knowledge and behavior still exist in Nigeria as evident in the increased knowledge about HIV reported among young persons ${ }^{9}$.

The findings of this study corroborate those from other studies conducted in low and middle-income countries ${ }^{1,19,25,27}$. Gender seems to be a major determinant of comprehensive knowledge of HIV among young people in Nigeria. Female youth are less likely to have comprehensive knowledge of HIV than their male counterparts. In contrast, a study conducted among Filipino youth reported significantly lower AIDS knowledge among males than females ${ }^{27}$ and in 
Table 2: Meta-analysis of Determinants of Comprehensive Knowledge of HIV among Young People in Nigeria (2003-2013)

\begin{tabular}{|c|c|c|c|c|}
\hline & $\begin{array}{l}\text { Year } 2003 \\
\text { CRR(95\%CI) } \\
\end{array}$ & $\begin{array}{l}\text { Year } 2008 \\
\text { CRR(95\%CI) } \\
\end{array}$ & $\begin{array}{l}\text { Year } 2013 \\
\text { CRR(95\% CI) } \\
\end{array}$ & $\begin{array}{l}\text { M-H pooled } \\
\text { CRR }(95 \% \text { CI }) \\
\end{array}$ \\
\hline \multicolumn{5}{|l|}{ Sex } \\
\hline Male & 1.00 & 1.00 & 1.00 & 1.00 \\
\hline Female & $0.80(0.68,0.95)$ & $0.68(0.65,0.72)$ & $0.72(0.69,0.76)$ & $0.71(0.69,0.73)$ \\
\hline \multicolumn{5}{|l|}{ Age } \\
\hline $15-19$ & 1.00 & 1.00 & 1.00 & 1.00 \\
\hline $20-24$ & $1.68(1.45,1.95)$ & $1.28(1.22,1.35)$ & $1.22(1.17,1.28)$ & $1.27(1.23,1.31)$ \\
\hline \multicolumn{5}{|l|}{ Education } \\
\hline None & 1.00 & 1.00 & 1.00 & 1.00 \\
\hline Primary & $1.00(0.77,1.31)$ & $1.58(1.39,1.78)$ & $1.18(1.07,1.29)$ & $1.29(1.20,1.38)$ \\
\hline Secondary & $1.75(1.44,2.13)$ & $2.81(2.56,3.08)$ & $1.67(1.57,1.78)$ & $2.01(1.92,2.12)$ \\
\hline Higher & $4.09(3.20,5.22)$ & $4.31(3.87,4.81)$ & $2.70(2.50,2.93)$ & $3.29(3.09,3.50)$ \\
\hline \multicolumn{5}{|l|}{ Marital status } \\
\hline Never married & 1.00 & 1.00 & 1.00 & 1.00 \\
\hline Currently married & $0.85(0.73,0.99)$ & $0.61(0.58,0.65)$ & $0.78(0.74,0.82)$ & $0.71(0.68,0.74)$ \\
\hline Formerly married & $0.66(0.34,1.27)$ & $0.71(0.53,0.95)$ & $1.00(0.82,1.22)$ & $0.86(0.73,1.01)$ \\
\hline \multicolumn{5}{|l|}{ Religion } \\
\hline Christians & 1.00 & 1.00 & 1.00 & 1.00 \\
\hline Muslims & $0.93(0.80,1.07)$ & $0.70(0.67,0.74)$ & $1.04(0.99,1.09)$ & $0.88(0.85,0.91)$ \\
\hline Others & $0.26(0.04,1.79)$ & $0.77(0.61,0.97)$ & $0.66(0.50,0.97)$ & $0.70(0.59,0.84)$ \\
\hline \multicolumn{5}{|l|}{ Place of residence } \\
\hline Urban & 1.00 & 1.00 & 1.00 & 1.00 \\
\hline Rural & $0.50(0.43,0.58)$ & $0.64(0.60,0.67)$ & $0.68(0.65,0.71)$ & $0.65(0.63,0.67)$ \\
\hline \multicolumn{5}{|l|}{ Region } \\
\hline Northern & 1.00 & 1.00 & 1.00 & 1.00 \\
\hline Southern & $1.28(1.11,1.48)$ & $1.28(1.22,1.35)$ & $0.93(0.89,0.97)$ & $1.08(1.05,1.12)$ \\
\hline \multicolumn{5}{|c|}{ Household Wealth Index } \\
\hline Poor & 1.00 & 1.00 & 1.00 & 1.00 \\
\hline Average & $1.61(1.25,2.06)$ & $1.68(1.54,1.83)$ & $1.37(1.28,1.46)$ & $1.49(1.42,1.57)$ \\
\hline Rich & $2.68(2.20,3.26)$ & $2.26(2.11,2.42)$ & $1.72(1.63,1.82)$ & $1.97(1.89,2.05)$ \\
\hline \multicolumn{5}{|l|}{ HIV test before } \\
\hline No & 1.00 & 1.00 & 1.00 & 1.00 \\
\hline Yes & $1.82(1.48,2.25)$ & $1.52(1.42,1.63)$ & $1.38(1.31,1.45)$ & $1.44(1.38,1.50)$ \\
\hline
\end{tabular}

\section{$\mathbf{C R R}=$ Crude $\mathbf{R R}$}

another study among rural youth in India, no significant difference in knowledge between males and females was reported ${ }^{18}$.

The gender differential in comprehensive knowledge of HIV may have implications for HIV prevention interventions in Nigeria given the higher prevalence of HIV among young women than their counterpart men ${ }^{3}$. Ochako et al therefore recommended that while targeting both young women and men with education on HIV prevention, additional concerted efforts should also be directed at young women ${ }^{16}$. The reasons for the gender disparity in comprehensive knowledge of HIV in Nigeria need to be further investigated through qualitative inquiries.
Similar to other studies ${ }^{16,18,27-33}$, age is another significant determinant observed in this study. Although it is difficult to ascertain the reasons for the low comprehensive knowledge of HIV among adolescents in Nigeria; we do know from previous research that because adolescents and young persons have limited knowledge about the disease ${ }^{30}$ and they are often ignorant about their vulnerabilities and levels of risk $^{34}$, they are more likely to convey contradictory messages about HIV transmission $^{35}$ especially as peer influences increase during late adolescence and early adulthood $^{36-40}$. Sexual experience, lower uptake of STI/HIV testing and less condom use which have been linked with lower knowledge of HIV among 
Table 3: Log-binomial Regression Model of Comprehensive Knowledge of HIV among Young People in Nigeria (2003-2013)

\begin{tabular}{|c|c|c|}
\hline & Adjusted RR(95\%CI) & p-value \\
\hline \multicolumn{3}{|l|}{ Survey year } \\
\hline 2003 & 1.00 & \\
\hline 2008 & $1.50(1.37,1.64)$ & $<0.001$ \\
\hline 2013 & $1.50(1.37,1.64)$ & $<0.001$ \\
\hline \multicolumn{3}{|l|}{ Sex } \\
\hline Male & 1.00 & \\
\hline Female & $0.77(0.74,0.80)$ & $<0.001$ \\
\hline \multicolumn{3}{|l|}{ Age } \\
\hline $15-19$ & 1.00 & \\
\hline $20-24$ & $1.18(1.13,1.23)$ & $<0.001$ \\
\hline \multicolumn{3}{|l|}{ Education } \\
\hline None & 1.00 & \\
\hline Primary & $1.21(1.12,1.32)$ & $<0.001$ \\
\hline Secondary & $1.75(1.62,1.88)$ & $<0.001$ \\
\hline Higher & $2.27(2.07,2.49)$ & $<0.001$ \\
\hline \multicolumn{3}{|l|}{ Marital status } \\
\hline Never married & 1.00 & \\
\hline Currently married & $0.99(0.93,1.04)$ & 0.592 \\
\hline \multicolumn{2}{|l|}{ Religion } & 0.431 \\
\hline Christians & 1.00 & \\
\hline Muslims & $1.08(1.03,1.13)$ & 0.001 \\
\hline Others & $0.95(0.79,1.14)$ & 0.569 \\
\hline \multicolumn{3}{|l|}{ Place of residence } \\
\hline Urban & 1.00 & \\
\hline Rural & $0.88(0.85,0.92)$ & $<0.001$ \\
\hline \multicolumn{3}{|l|}{ Region } \\
\hline Northern & 1.00 & \\
\hline Southern & $0.77(0.74,0.81)$ & $<0.001$ \\
\hline \multicolumn{3}{|l|}{ Wealth Index } \\
\hline Poor & 1.00 & \\
\hline Average & $1.22(1.15,1.30)$ & $<0.001$ \\
\hline Rich & $1.40(1.32,1.48)$ & $<0.001$ \\
\hline \multicolumn{3}{|l|}{ HIV test before } \\
\hline No & 1.00 & \\
\hline Yes & $1.15(1.09,1.21)$ & $<0.001$ \\
\hline No response & $0.43(0.35,0.54)$ & $<0.001$ \\
\hline
\end{tabular}

low-income African American adolescents ${ }^{41}$ could also be the underlying factors responsible for the insufficiency in comprehensive knowledge of HIV among adolescents in Nigeria. Lack of accurate knowledge about HIV/AIDS among youth has also been linked with a dearth of comprehensive sexuality and HIV education coupled with likely inaccuracies in abstinence-only curricula used by some school systems ${ }^{42}$.

As in other studies ${ }^{12,16,18,20,23,24,27,43}$, education is a major driver of comprehensive knowledge of HIV in this study. Thus, comprehensive knowledge of HIV among young people in Nigeria is a function of educational attainment. To this effect, several adolescents and youth-focused HIV prevention interventions in school settings have been established since around 2000. One of such interventions is the National Youth Service Corps (NYSC) Peer Education Training Scheme (PETS), where volunteer corps members are trained as peer educators and trainers and deployed as teachers to various schools throughout Nigeria to increase the knowledge of their peers on HIV and motivate them to adopt preventive behavior ${ }^{44}$ and also spread the information in their community ${ }^{45}$. Another major youth focused school-based HIV/AIDS intervention proven to be effective among adolescents with hearing impairment in some states in Nigeria ${ }^{46}$, is the Family Life and HIV/AIDS Education (FLHE) curriculum introduced in 2003 as the main Education Sector Response to HIV/AIDS in Nigeria ${ }^{47}$. Unfortunately, these interventions by their design are targeted at only young people in secondary and tertiary institutions of learning leaving a teeming population of out-ofschool adolescents and youth without HIV prevention interventions. . The 2008 NDHS showed that about $27 \%$ of youth (aged 15-24) in Nigeria had no education ${ }^{14}$ which is too huge a population to ignore in the national HIV response to improve their comprehensive knowledge of HIV, stimulate behavioral change and reduce new HIV infections.

In consonance with previous studies ${ }^{18-20}$, 27,33 , the current study has shown that rural youth in Nigeria could be more vulnerable than urban youth because of their consistently lower level of comprehensive knowledge of HIV for over a decade (2003-2013). A probable reason for the deficit in comprehensive knowledge of HIV among youth residing in rural areas could be limited access to HIV prevention information. Findings from some studies ${ }^{23,24}$ have shown that much of the large rural-urban differences in mean knowledge is due to differences in schooling/education, exposure to mass media and wealth. Thus, education plays a significant role in determining adolescents and youth's socio-economic status and in influencing comprehensive knowledge of HIV.

As in other studies ${ }^{35,48}$, wealth status of households of young people also seems to play a significant role in shaping the level of 
comprehensive knowledge of HIV among young people in Nigeria. For instance, among unmarried youth in Cameroon, living in poor households and disadvantaged neighborhoods significantly increased inaccurate knowledge of HIV transmission modes and prevention strategies ${ }^{35}$; while in eastern Ethiopia, comprehensive knowledge of HIV and AIDS was better among inschool adolescents from families with a relatively middle or high wealth index ${ }^{48}$. In this study, youth from average and rich households respectively had more comprehensive knowledge of HIV significantly more than youth from poor households.

The regional differential in comprehensive knowledge of HIV observed among young people in this study is noteworthy. However, deducing the probable reasons for the regional disparity is beyond the scope of this present study. Further research will be required to gain insight into regional differential in comprehensive knowledge among youth in Nigeria.

Uptake of HIV test ${ }^{16}$ is also a significant determinant of comprehensive knowledge of HIV among young people in Nigeria. HIV testing is likely to increase comprehensive knowledge of HIV because of the pre- and post-test HIV counseling which is an integral part of HIV testing in Nigeria ${ }^{49-51}$. Although a similar study conducted among young urban women in Kenya ${ }^{16}$ showed that knowing someone who has HIV or died of AIDS was predictive of having comprehensive knowledge of HIV, in this study, knowing someone who has HIV or has died of AIDS was marginally correlated with comprehensive knowledge of HIV among those aged 15-24. This could be attributed to the high level of awareness of HIV/AIDS in the country resulting from mass media campaigns during that period.

A major strength of this study is the use of three cycles of large national datasets spanning a decade to assess the trend and determinants of comprehensive knowledge of HIV among young people. Nonetheless, this study is not without some limitations. It was based on further analysis of data collected in three cross-sectional surveys. By design, cross-sectional surveys are weak in establishing temporal relationships between the exposure and the outcome. Although this study presents important information on the knowledge of HIV among Nigerian youth over ten years, with implications for programming to reduce the prevalence and incidence of the disease in the country, the datasets are four years behind time limiting its generalizability to the current situation in 2017. It is plausible that the increase in comprehensive knowledge of HIV observed in this study would be sustained through 2017 for adolescents and youth in schools and not necessarily for out-of-school youth. The findings of this study reveal that the national HIV response falls short of the needs and expectations of young people in the areas of HIV education and appropriate access to youth friendly services especially for the most vulnerable groups of youth. Besides the Family Life HIV and AIDS Education program and the National Youth Service Corps (NYSC) Peer Education Training Scheme (PETS) both designed to improve the knowledge of inschool adolescents and youth, programs covering out-of-school youth are few, and small in scale.

The recently launched National HIV Strategy for Adolescent and Young people (20162020) by the National Agency for the control of AIDS (NACA) to reduce new HIV infections among adolescents and young people in Nigeria targeting in-school youth, out-of-school youth, and key populations at higher risk is a welcome development. In addition, there should be improved resourcing (funding, personnel, infrastructure \& supplies) of programs and services especially targeted at female adolescents and youth, the rural and poor urban youth, out-ofschool youth, and young key populations who are systematically left out of national HIV prevention programs.

\section{Conclusion}

High levels of awareness of HIV and AIDS in Nigeria have not translated into high level of comprehensive knowledge of HIV and AIDS necessary for HIV prevention. With the right skills and knowledge, young people have a positive influence on their peers. However, this study shows that comprehensive knowledge of HIV among young people (aged 15-24) in Nigeria increased between 2003 and 2013 although it falls 
short of the global expectation for young people. Determinants of comprehensive knowledge include gender, age, and place of residence, education, household wealth index, and uptake of HIV test. Specifically, female adolescents and young adults, those aged 15-19 years, those with no formal education, those from poor households, those residing in rural areas or in the southern regions of Nigeria, and those who had never had HIV test before had lower comprehensive knowledge of HIV.

Our findings therefore suggest the need to intensify efforts in ensuring that all on-going and future youth-focused interventions in the country meet the knowledge (sexual health and HIV/AIDS) needs of these sub-populations of young people in Nigeria. However, there are still several policy issues hampering the national response to young people's sexual and reproductive health in Nigeria, which must be addressed to create an enabling environment that would allow SRH programming for young people to thrive.

\section{Competing Interests}

The authors declare that they have no competing interests.

\section{Authors' Contributions}

$\mathrm{AB}, \mathrm{BA}$ and $\mathrm{SB}$ conceived the study; $\mathrm{AB}$ obtained the dataset from the DHS Program, conducted data analysis and participated in writing the manuscripts; SB reviewed and contributed to the manuscripts; BA reviewed and contributed to the manuscripts. All authors read and approved the final manuscript.

\section{Acknowledgement}

We acknowledge Dr. George Eluwa for his contribution to conception and design of this study. We also acknowledge the support of the DHS Program and ICF International for the release of the NDHS dataset used for this study.

\section{References}

1. UNAIDS. World AIDS Day Report, 2011.

2. WHO, UNAIDS, UNICEF. Global HIV/AIDS Response -
Epidemic update and health sector progress towards Universal Access. Progress Report, 2011.

3. UNAIDS. The Gap Report: Begining of the End of the AIDS Epidemic, 2014.

4. Federal Ministry of Health [Nigeria]. 2007 National HIV \& AIDS and Reproductive Health Survey Plus: Federal Ministry of Health National AIDS/STI Control Programme, 2008.

5. Federal Ministry of Health [Nigeria]. National HIV \& AIDS and Reproductive Health Survey, 2012 (NARHS Plus): Federal Ministry of Health Abuja, Nigeria, 2013.

6. United Nations Children's Fund, Joint United Nations Programme on HIV/AIDS, World Health Organization. Young People and HIV/AIDS: Opportunity in Crisis, 2002.

7. UNAIDS/09.10E / JC1676E. Monitoring the Declaration of Commitment on HIV/AIDS : guidelines on construction of core indicators : 2010 reporting., 2010.

8. United Nations Children's Fund (UNICEF). Opportunity in Crisis: Preventing HIV from early adolescence to young adulthood, 2011

9. UNAIDS. UNAIDS Report on the global AIDS Epidemic Global Report, 2010

10. USAID. HIV/AIDS Health Profile Sub-Saharan Africa, 2011.

11. Global Interagency Task Team on HIV and young people. Securing The Future Today. Synthesis of Strategic Information on HIV and Young People. Geneva: UNAIDS, 2011:1-80.

12. Cicciò 1 and Sera D. Assessing the knowledge and behavior towards HIV/AIDS among youth in northern uganda: a cross-sectional survey. Giornale Italiano Di Medicina Tropicale 2010;15(1-4):29-34.

13. National Population Commission (NPC) [Nigeria] and ICF International. Nigeria Demographic and Health Survey 2013. Abuja, Nigeria and Rockville, Maryland, USA: NPC and ICF International., 2014.

14. National Population Commission (NPC) [Nigeria] and ICF Macro. Nigeria Demographic and Health Survey 2008. Abuja, Nigeria: National Population Commission and ICF Macro, 2009.

15. National Population Commission (NPC) [Nigeria] and ORC Macro. Nigeria Demographic and Health Survey 2003. Calverton, Maryland: National Population Commission and ORC Macro, 2004.

16. Ochako R, Ulwodi D, Njagi P, Kimetu S and Onyango A. Trends and deteriminants of Comprehensive HIV and AIDS knowledge among urban young women in Kenya. AIDS Research and Therapy 2011;8(11).

17. Fako T, Kangara L and Forcheh N. Predictors of knowledge about HIV/AIDS among young people: Lesson from Botswana. Journal of AIDS and HIV Research 2010;2(6):116-30.

18. Yadav S, Makwana N, Vadera B, Dhaduk K and Gandha K. Awareness of HIV/AIDS among rural youth in India: A community based cross-sectional study. J Infect Dev Ctries 2011;5(10):711-16.

19. Li X, Lin C, Gao Z, Stanton B, Fang X, Yin Q and Wu Y. 
HIV/AIDS knowledge and the implications for health promotion programs among Chinese college students: geographic, gender and age differences. Health Promotion International 2004;19(3).

20. Siziya S, Muula A and Rudatsikira E. HIV and AIDSrelated knowledge among women in Iraq. BMC Research Note 2008;1(123).

21. Omeonu P and Kollie E. Knowledge and attitude of Babcock University students on risk behaviours of HIV/AIDS. Journal of Life \& Physical Sciences, acta SATECH 2010;3(2):135-42.

22. Lammers J, van Wijnbergen S and Willebrands D. Gender Differences, HIV Risk Perception and Condom Use, 2011.

23. Rahnman M. Determinants of knowledge and awareness about AIDS: Urban-rural differentials in Bangladesh. Journal of Public Health and Epidemiology 2009;1(1):014-21.

24. Glick P, Randriamamonjy J and Sahn D. Determinants of HIV Knowledge and Condom Use among Women in Madagascar: An analysis Uisng Matched Household and community Data, 2008.

25. Mishra V, Agrawal P, Alva S, Gu Y and Wang S. Changes in HIV-Related Knowledge and Behaviors in SubSaharan Africa. No. 24. Calverton, Maryland, USA: ICF Macro, 2009.

26. Statement to the Forty-fifth session of the Commission on Population and Development Special Theme: Adolescents and Youth. New York, 2012.

27. Knowledge of HIV/AIDS and Unsafe sex practices among Filipino youth.; 2004; Boston, Massachusetts.

28. Shweta C, Mundkur S and Chaitanya V. Knowledge and Beliefs about HIV/AIDS among Adolescents. WebmedCentral PAEDIATRICS 2011;2(12:WMC002830).

29. Asekun-Olarinmoye E, Olajide F and Asekun-Olarinmoye I. HIV/AIDS Preventive Measures among In-school Adolescents in a Sub-Urban Community in Southwestern Nigeria. actaSATECH 2011;4(1):8196.

30. Singh A and Jain S. Awareness of HIV/AIDS Among School Adolescents in Banaskantha District of Gujarat Health and Population: Perspectives and Issues 2009;32(2):59.65.

31. Diala C, Olujimi S, Harris F and Feyisetan K. HIV-Related Knowledge, Attitudes, Behaviors, and Practices of Young People in Cross River State and Kogi State, Nigeria. Washington DC: C-Change, 2011.

32. Rahman MM, Kabir M and Shahidullah M. Adolescent Knowledge and Awareness about AIDS/HIV and Factors affecting them in Bangladesh. J Ayub Med Coll Abbottabad 2009;21(3).

33. Peltzer K and Promtussananon S. HIV/AIDS Knowledge and Sexual Behavior Among Junior Secondary School Students in South Africa. Journal of Social Sciences 2005;1(1):1-8.

34. Sawhney S and Koul S. AIDS - Knowledge and Information needs of Adolescent Girls (16-18 yrs) of Jammu. International Journal of Scientific and Research Publications 2011;2(10).
35. Dimbuene Z and Defo B. Fostering accurate HIV/AIDS knowledge among unmarried youths in Cameroon: Do family environment and peers matter? BMC Public Health 2011;11:348.

36. Speizer I, Magnani R and Colvin C. The effectiveness of adolescent reproductive health interventions in developing countries: A review of the evidence. Journal of Adolescent Health 2003;33(5):324-48.

37. Perrino T, González-Soldevilla A, Pantin $\mathrm{H}$ and Szapocznik J. The role of families in adolescent HIV prevention: A review. Clinical Child and Family. Psychology Review 2000;3(2):81-96.

38. Whitaker D and Miller K. Parent-adolescent discussions about sex and condoms: Impact on peer influences of sexual risk behavior. Journal of Adolescent Research 2000;15(2):251-73.

39. Lefkowitz E, Boone T and Shearer C. Communication with best friends about sex-related topics during emerging adulthood. Journal of Youth and Adolescence 2004;33(4):339-51.

40.Campbell C and MacPhail C. Peer education, gender and the development of critical consciousness: Participatory HIV prevention by South African Youth. 2002;55(2):331-45.

41. Swenson RR, Rizzo CJ, Brown LK, Vanable PA, Carey MP, Valois RF, DiClemente RJ and Romer D. HIV Knowledge and its Contribution to Sexual Health Behaviors of Low-Income African American Adolescents. J Natl Med Assoc 2010;102(12):117382.

42. amfAR. Youth and HIV/AIDS in the United States: Challenges and Opportunities for Prevention. Issue Brief, 2010.

43. Anwar M, Sulaiman SAS, Ahmadi K and Khan TM. Awareness of school students on sexually transmitted infections (STIs) and their sexual behavior: a cross-sectional study conducted inPulau Pinang, Malaysia. BMC Public Health 2010;10(47).

44. UNICEF Nigeria. HIV/AIDS-Action.

45. UNICEF/National Youth Service Corps Peer education training project in Nigera and Challenges.XVI International AIDS Conference 2006.

46. Adeniyi S, Oyewumi M and Fakolade A. An Assessment of the Level of Influence of Family Life and HIV/AIDS Education on HIV/AIDS related Knolwedge, Attitude and Decision making among Adolescents with Hearing impairment in some States in Nigeria. The African Symposium 2010;10(2):60-68.

47. Nigerian Educational Research and Development Council (NERDC). Family Life and HIV Education Curriculum for Junior Secondary Schools: Federal Ministry of Education, igerian Educational Research and Development Council (NERDC), Universal Basic Education (UBE), Action Health Incorporated (AHI), 2003.

48. Oljira L, Berhane Y and Worku A. Assessment of comprehensive HIV/AIDS knowledge level among in-school adolescents in eastern Ethiopia. Journal 
of the International AIDS Society 2013;16 (17349).

49. National Agency for Control of AIDS (NACA). Federal Governement of Nigeria National Policy on HIV/AIDS, 2009.

50. South African Government Information. HIV Couselling and Testing. FAQs-HIV/AIDS, 2011.

51. Fischer S, Reynolds H, Yacobson I, Barnett B and
Schueller J. HIV Counseling and Testing for Youth. A Manual for Providers: USAID and FHI, 2007.

52. NACA National HIV Strategy of Adolescents and Young $\begin{array}{llll}\text { People } & 2016 & - & 2020 .\end{array}$ http://www.ilo.org/wcmsp5/groups/public/-ed_protect/---protrav/---

ilo_aids/documents/legaldocument/wcms_532857.p df. 